\title{
Investigation of concrete pavement cracking under multi-head impact loading via the continuum-discontinuum element method
}

\author{
Zhang Qunlei $^{\mathrm{a}}$, Zhi Zihan ${ }^{\mathrm{a}}$, Feng Chun ${ }^{\mathrm{b}}$, Cai Yingchun ${ }^{\mathrm{a}}$, Pang Guanhong ${ }^{\mathrm{a}}$, Yue Jinchao ${ }^{\mathrm{a}, *}$ \\ ${ }^{a}$ School of Water Conservancy Engineering, Zhengzhou University, Zhengzhou 450001, China \\ ${ }^{\mathrm{b}}$ Institute of Mechanics, Chinese Academy of Sciences, Beijing 100190, China
}

\section{A R T I C L E I N F O}

\section{Keyword:}

Concrete pavement

Mesoscopic simulation

Three-dimensional aggregate

Cohesive model

Impact cracking

\begin{abstract}
A B S T R A C T
To accurately and effectively simulate the cracking and crushing process of concrete pavement under multi-head impact loading, a large-scale road 3D model that considers concrete pavement, subgrade and soil foundation is established. Then, the discontinuum element method is applied in the concrete pavement's potential fracture area, and the continuum element method is applied in the hammer body and the non-fracture area of concrete pavement. A cohesive model is applied to the element interface of the concrete fracture area, and a contact element is used to deal with the interaction between the hammer body and the pavement. Mesoscopic simulations on the impact cracking process of concrete pavement are conducted by considering the element shapes, three-dimensional aggregates, impact locations and impact velocities. Finally, impact testing and core drilling are conducted in the field to evaluate the simulation results. The results demonstrate that the cracking and crushing process of concrete pavement can be quickly simulated via the continuum-discontinuum element method (CDEM), and the simulation results agree with the results of the in-site tests. The concrete pavement model that is meshed by tetrahedral elements and includes aggregates can result in a higher calculation efficiency and superior impact cracking performance. Concrete pavement is severely crushed in the impact contact area, closed quadrangle crack surfaces form along the inside of four hammerheads, and tension crack surfaces mainly propagate along the long axis of the rectangular hammerheads. The impact locations mainly affect the crack distribution of the concrete pavement, and the impact velocities determine the fracture degree. As the impact velocity increases, the impact force linearly changes, whereas the fracture degree varies according to a power function. Overall, the influence of the impact velocities on concrete cracking is greater than the impact locations.
\end{abstract}

\section{Introduction}

Concrete slab structures are widely used in roads, airports and various municipal and hydraulic projects due to their convenient construction and strong bearing capacity. However, serious damages have appeared on concrete slab structures with the increase of the service life. To ensure normal use, various techniques for rehabilitation, demolition and reconstruction have been proposed. For example, concrete pavement is widely used in roads. The longer service life and high traffic flow cause serious damage to the pavement. Therefore, the rehabilitation of concrete pavement is urgent. For in-site treatment and disposal of old concrete pavement, the pavement is typically crushed and hot mix asphalt concrete pavement is laid. [1] The crushing methods of concrete pavement include the application of a multi-head breaker, impact roller crushing, a guillotine breaker, a resonant pavement breaker, and microcrack homogenization crushing. [2-6] Micro-crack homogenization crushing technology is widely used for the rehabilitation of concrete pavement in China. As shown in Fig. 1, the equipment impacts and crushes the pavement using a heavy hammer inside a cage. After the crushing, the pavement has uniformly distributed micro-cracks, and hot mix asphalt concrete is directly overlaid on the pavement. As a result, the warpage deformation is reduced, and the joint deflection difference can also be eliminated. The rubblization construction technology of old concrete pavement under low-speed impact loading is an important technique for realizing its homogeneous regeneration and utilization; hence, research on the fracture mechanism and influencing factors of old concrete pavement is essential. However, few studies have been conducted on the crack surface propagation inside concrete pavement and the factors that affect the pavement impact cracking.

\footnotetext{
* Corresponding author.

E-mail address: yuejc@zzu.edu.cn (J. Yue).
} 


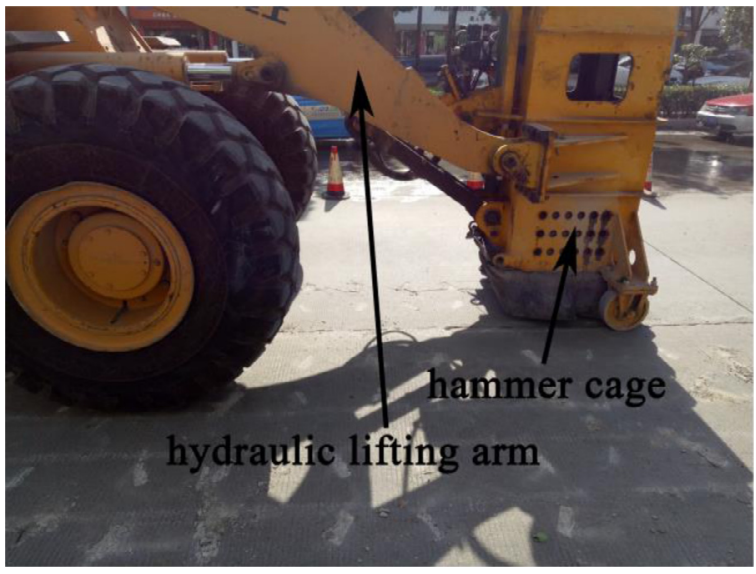

Fig. 1. Micro-crack homogenization crushing technology.

Many experimental studies have been conducted on the impact resistance of concrete slab structures. Chen et al. [7] investigated the high-mass, low-velocity impact behaviour of reinforced concrete members, including beams and slabs. Dey et al. [8] investigated the impact response of fibre-reinforced aerated concrete using an instrumented impact device with a three-point bending configuration. Using a drop-weight impact test machine, Yoo et al. [9] conducted impact testing to estimate the impact resistance of steel-fibre-reinforced concrete slabs that were strengthened with fibre-reinforced polymer sheets. Zhang et al. [10] investigated the flexural impact responses of steel-fibre-reinforced concrete and studied the effects of the hammer weight and drop height on the impact performance of steel-fibre- and polypropylene-fibre-reinforced concretes. The effect of the support condition on the slab impact behaviour was investigated via impact loading tests. [11] Radnic et al. [12] investigated the impact behaviour of two-way conventional reinforced concrete slabs and identical slabs that were strengthened by carbon-fibre-reinforced polymer. Sakthivel et al. [13] developed hybrid steel-mesh-and-fibre-reinforced cementitious composites and studied their impact performance via low-velocity repeated drop weight impact tests. Yahaghi et al. [14] studied the impact resistance and cracking behaviour of lightweight concrete that was reinforced by polypropylene fibre. Elavarasi et al. [15] investigated the impact response of fibrous concrete thin slabs with and without reinforcement. However, making successive observations of the crack propagation process is difficult, and limited data on the impact cracking process of a concrete slab can be obtained in the experiment due to the complexity of concrete slab cracking under impact loading. Based on experiments, numerical simulation has become an effective approach for further studying the cracking mechanism of concrete slabs with the development of computer technology. Nia et al. [16] conducted an impact test based on the testing procedure that was recommended by ACI committee 544, and the results from simulations of plain concrete and fibre-reinforced concrete are compared with experimental testing data. Gopinath et al. [17] conducted experimental and numerical investigations on fabric-reinforced concrete and ultra-high-strength concrete panels under low-velocity impact loading. Othman et al. [18] established a three-dimensional finite element model for simulating the dynamic response of ultra-high-performance fibre-reinforced concrete plates in impact testing. Xiao et al. [19] proposed a two-degree-offreedom dynamic model for predicting the response of reinforced concrete slabs that are subjected to low-velocity impacts. Zhao et al. [20] investigated the impact response of SC panels via drop hammer tests and numerical simulations. Pham et al. [21] investigated the effects of the contact stiffness on the impact behaviour of RC beams experimentally and via simulation. Based on the fictitious crack model (FCM) of Hillerborg, many experimental and numerical studies have been conducted. Damage fracture criteria that consider the fracture energy have been the main criteria in concrete cracking simulation. [22-27] Gui et al. [28] investigated the dynamic failure of brittle rocks via a hybrid continuum-discrete element method with a mixed-mode cohesive fracture model. The model combines the tension, compression and shear material behaviours of rocks.

The studies on concrete failure that are discussed above focus mainly on concrete members, and an understanding of the pavement fracture mechanics is important. The potential for mixed-mode fracture at the interface between concrete composite pavements and overlays is evaluated via the combination of a three-dimensional lattice model of the region of interest and a plate finite element model of the surrounding structure. [29] Ramsamooj applied linear elastic fracture mechanics to pavement response models, and later developed stress intensity factors for finite element analysis or layered elastic analysis models. [30,31] Finite element modelling was successfully used to analyse concrete pavements with partial-depth cracks via the introduction of fracture mechanics into pavement design and analysis. [32] Ioannides summarized the state of the art in the application of fracture mechanics to pavement engineering; according to Ioannides, the specimen size effect is of substantial concern in such applications. [33] A two-step fracture-mechanics-based model was developed for predicting the occurrence potential of delamination in continuously reinforced concrete pavements. [34] Aure and Ioannides discussed the simulation of crack propagation in beam specimens; according to Aure and Ioannides, the beam-as-slab assumption cannot be directly transferred to in-field pavements, and the fracture mechanics and the size effect must be considered. [35] The fracture of concrete pavement is mainly caused by the development of internal micro-cracks, Aure and Ioannides conducted a numerical analysis of the fracture behaviour of pavement slabs and a finite element analysis of crack propagation in pavement slabs-on-grade with aggregate interlocking joints. [36,37]

Concrete structure failure is mainly analysed via FEM, which can accurately calculate the stress of a continuous structure but cannot well simulate the fracturing and crushing processes. For large-scale projects, DEM can simulate the fracturing process of concrete. However, DEM does not fully consider the effect of elastic deformation on the crushing process. Moreover, it requires a large amount of calculation time. The continuum-discontinuum element method (CDEM) [38-42] can fully consider the elastic deformation of a large-scale structure. It also can quickly simulate the crack propagation process. Based on CDEM, the deformation and force of a concrete pavement structure can be accurately calculated via the continuous element method. The interaction between a drop hammer and concrete pavement can be transmitted by a contact element. Combined with a damage fracture criterion that considers the concrete fracture energy, the cracking process of concrete pavement under impact loading can be simulated by the fracture of contact elements. Therefore, CDEM is a more suitable method for simulating the impact cracking process of a concrete pavement structure. However, under multi-head impact loading and considering the random aggregates and concrete fracture energy, the three-dimensional simulation of concrete pavement cracking via CDEM has not been reported in the literature.

In this paper, a full-scale road 3D numerical model that considers concrete pavement, subgrade and soil foundation is established, and the three-dimensional random aggregates in the concrete pavement are also generated. The damage fracture criterion of maximum tensile stress with consideration of the concrete tensile fracture energy and the Mohr Coulomb damage fracture criterion with consideration of the concrete shear fracture energy are applied to the element interface of the concrete fracture area. Moreover, a normal contact element is used to model the contact between the drop hammer and the concrete pavement. After that, concrete impact cracking simulations, in which various element shapes, impact locations and impact velocities are considered, are conducted via the coupled calculation of continuous and discontinuous elements. In addition, the cracking mechanism of concrete pavement under multi-head impact loading is examined by 


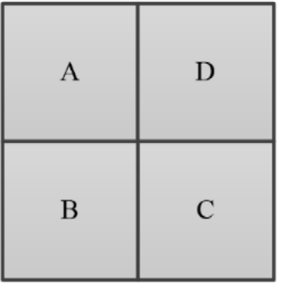

(a)

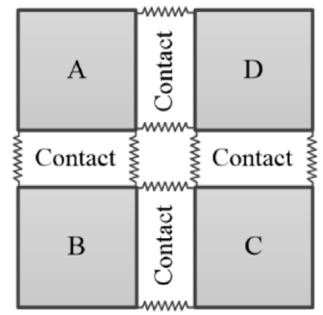

(b)

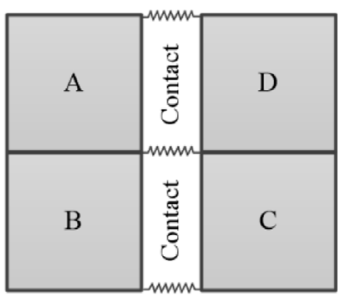

(c)

Fig. 2. Comparison of the computational domains: (a) FEM, (b) DEM and (c) CDEM.

analysing the fracture degree and the impact force. Finally, an impact experiment and drilling of a core of the concrete pavement are conducted in the field to evaluate the simulation results.

\section{Numerical method}

\subsection{Fundamentals of CDEM}

The computational domains are the continuous state, the discontinuous state, and the partially continuous state, which correspond to the FEM, DEM and CDEM domains, [38] respectively, as shown in Fig. 2. Conventionally, the FEM domain is used for fully continuous problems and the DEM domain for fully discontinuous problems. The continuum-discontinuum element method (CDEM) couples finite element calculations with discrete element calculations. It conducts finite element calculations inside the block elements and conducts discrete element calculations at the block element boundaries.

The calculation method is a time-stepping, explicit scheme. CDEM can be used to model static or dynamic problems through a system of equilibrium equations of the following matrix form:

$[M]\{\ddot{u}\}+[C]\{\dot{u}\}+[K]\{u\}=\{F\}_{\text {ext }}$

$\{F\}_{\text {ext }}=\{F\}_{b}+\{F\}_{s}+\{F\}_{t}$

where $[M]$ denotes the nodal mass matrix; $[C]$ is the damping matrix; $[K]$ denotes the stiffness matrix; $\{u\}$ denotes the displacement vector; and $\{F\}_{\text {ext }}$ denotes the vector of external forces, which include the body force $\{F\}_{b}$, the spring force of contact $\{F\}_{K}$ and the boundary traction $\{F\}_{t}$.

In the continuous element method, the incremental method is used to calculate the elastic stress and deformation of the block element:

$$
\begin{aligned}
& \Delta \xi_{i}=B_{i} \cdot \Delta u \\
& \Delta \sigma_{i}=D \cdot \Delta \xi_{i} \\
& \sigma_{i}^{n}=\sigma_{i}^{0}+\Delta \sigma_{i} \\
& F_{b}=\sum_{i=1}^{N} B_{i}^{T} \cdot \sigma_{i}^{n} \cdot \omega_{i} \cdot J_{i}
\end{aligned}
$$

where $i$ is the element Gaussian point, $\Delta \xi_{i}$ is the incremental strain vector, $B_{i}$ is the strain matrix, $\Delta u$ is the node incremental displacement vector, $\Delta \sigma_{i}$ is the incremental stress vector, $D$ is the element elastic matrix, $\sigma_{i}^{n}$ is the total stress at the current step, $\sigma_{i}^{0}$ is the total stress at the previous step, $F_{b}$ is the node force vector, $N$ is the number of Gaussian points, $\omega_{i}$ is the integral coefficient, and $J_{i}$ is the Jacobian determinant value.

In the discontinuous element method, the normal and tangential contact forces of the contact element in the current time step and the next time step are calculated via the incremental method.

$F_{K n}\left(t_{1}\right)=F_{K n}\left(t_{0}\right)-k_{n} \cdot A_{c} \cdot \Delta d u_{n}$

$F_{K s}\left(t_{1}\right)=F_{K s}\left(t_{0}\right)-k_{s} \cdot A_{c} \cdot \Delta d u_{s}$

where $F_{k n}$ and $F_{k s}$ denote the normal and tangential spring forces of contact, respectively; $k_{n}$ and $k_{s}$ denote the normal and tangential stiffnesses, respectively; $A_{\mathrm{c}}$ is the contact element area; and $\Delta d u_{n}$ and $\Delta d u_{s}$ represent the relative displacements in the normal and tangential directions, respectively.

\subsection{Fracture criterion of CDEM}

Since the fictitious crack model (FCM) of Hillerborg is used to model concrete fracturing, many experimental and numerical studies have been conducted on improving FCM. [22-27] In this section, based on CDEM, the damage fracture criterion of maximum tensile stress with consideration of the concrete tensile fracture energy and the Mohr Coulomb damage fracture criterion with consideration of the concrete shear fracture energy are applied to the element interface of the concrete fracture area. The model presented does not directly include strain-rate effects. However, the references $[28,41]$ indicate that the load rate effects on the tensile and compressive strengths of the rock samples can be simulated with a mixed-mode cohesive fracture model. Moreover, the load rate effect are a consequence of the interplay between inertial effects and fracture at the micro scale, which are captured by modelling the material with the discrete element approach. [28]

The damage fracture criterion of maximum tensile stress with consideration of the tensile fracture energy of concrete is expressed as follows:

$$
\left.\begin{array}{l}
\text { if }-F_{\mathrm{n}}\left(t_{1}\right) \geq \sigma_{t}\left(t_{0}\right) A_{c} \\
\text { then } F_{\mathrm{n}}\left(t_{1}\right)=-\sigma_{t}\left(t_{0}\right) A_{c} \\
\sigma_{t}\left(t_{1}\right)=-\left(\sigma_{t 0}\right)^{2} \times \Delta u_{n} /\left(2 G_{f t}\right)+\sigma_{t 0}
\end{array}\right\}
$$

where $\sigma_{t 0}, \sigma\left(t_{0}\right)$ and $\sigma\left(t_{1}\right)$ are the tensile strengths of the interface spring element in the initial time step, the current time step and the next time step, respectively; $\Delta u_{n}$ denotes the relative displacements in the normal directions; and $G_{f t}$ represents the tensile fracture energy (Pa.m).

The Mohr Coulomb damage fracture criterion with consideration of the concrete shear fracture energy is expressed as follows:

$$
\left.\begin{array}{c}
\text { if } F_{\mathrm{s}}\left(t_{1}\right) \geq F_{\mathrm{n}}\left(t_{1}\right) \times \tan \phi+c\left(t_{0}\right) A_{c} \\
\text { then } F_{\mathrm{s}}\left(t_{1}\right)=F_{\mathrm{n}}\left(t_{1}\right) \times \tan \phi+c\left(t_{0}\right) A_{c} \\
c\left(t_{1}\right)=-\left(c_{0}\right)^{2} \times \Delta u_{s} /\left(2 G_{f s}\right)+c_{0}
\end{array}\right\}
$$

where $\phi$ denotes the internal friction angle of the contact element; $c_{0}, c$ $\left(t_{0}\right)$ and $c\left(t_{1}\right)$ denote the cohesion strengths in the initial time step, the current time step and the next time step, respectively; $\Delta u_{s}$ denotes the relative displacements in the tangential directions; and $G_{f s}$ represents the shear fracture energy (Pa.m).

\section{Simulation program}

\subsection{Numerical models of impact systems}

To investigate the concrete pavement cracking under multi-head impact loading, models of the drop hammer and concrete pavement structure are established according to the actual conditions, as illustrated in Fig. 3a-c. To improve the computational efficiency of largescale modelling, the concrete pavement middle area ( $3 \mathrm{~m} \times 5 \mathrm{~m} \times 0.26 \mathrm{~m}$ ) is considered, to focus on the impact cracking 


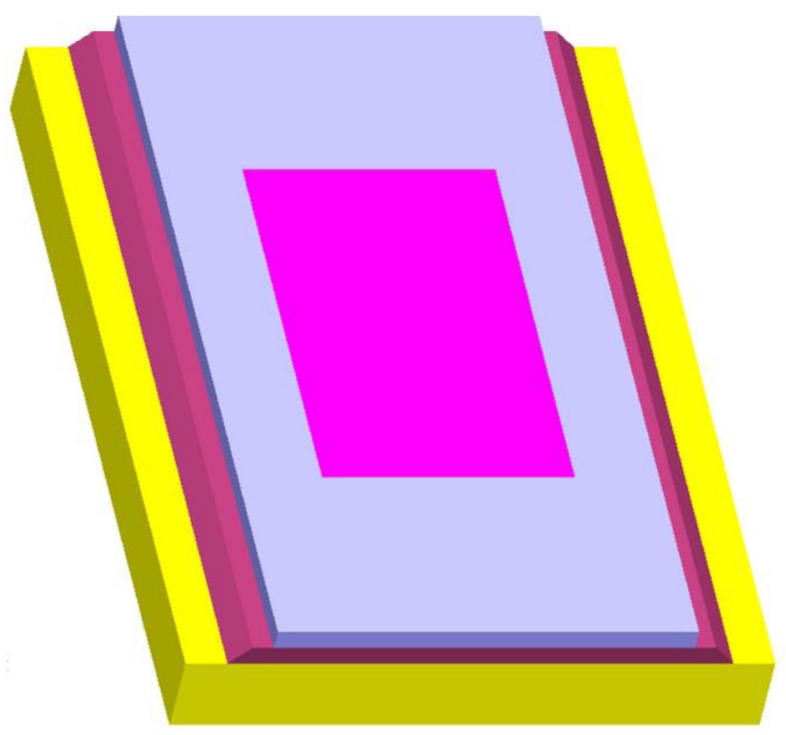

(a) Pavement structure model

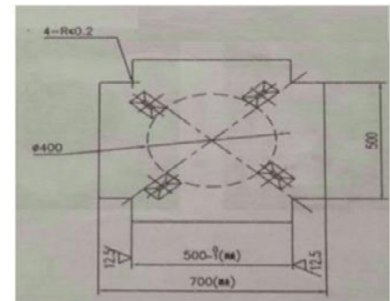

(b) Hammer design drawing

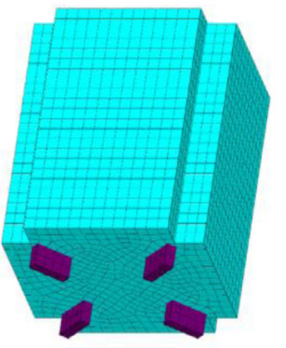

(c) Hammer model

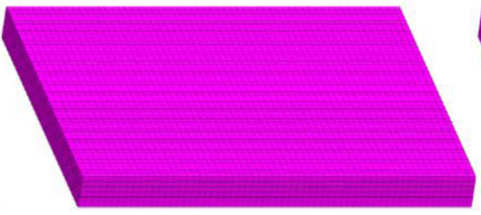

(d) Hexahedral element

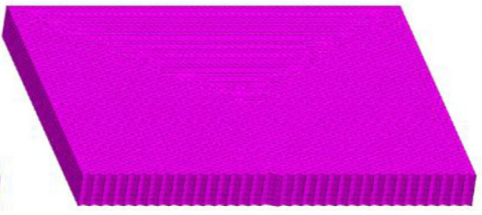

(e) Triangular prism element

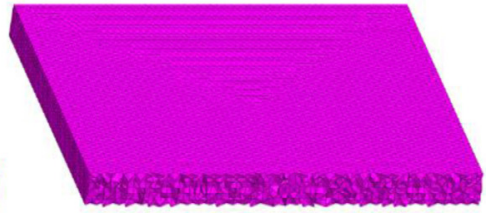

(f) Tetrahedral element

Fig. 3. Numerical models of concrete slab impact cracking.

mechanism of the concrete pavement. The simulation models are meshed mainly by hexahedral elements; however, triangular prism elements and tetrahedral elements are also used to mesh the area of $3 \mathrm{~m} \times 5 \mathrm{~m} \times 0.26 \mathrm{~m}$ to investigate the effects of the element shapes on the concrete cracking mechanism, as illustrated in Fig. 3d-f.

\subsection{Mesoscopic models of concrete pavement}

Concrete is composed of complex multi-phase-medium materials. However, the bearing capacity, the failure mode and the crack propagation paths of a concrete pavement structure are affected substantially by the concrete aggregates because the aggregate size, shape, surface roughness and distribution orientations are random. To study the impact cracking mechanism of the concrete pavement structure via simulation, it is important to create a three-dimensional model of the concrete pavement that reflects the aggregate randomness as accurately as possible. In this section, a concrete pavement model that includes three-dimensional random aggregates is generated, as illustrated in Fig. 4. To realize random crack propagation, the area $(3 \mathrm{~m} \times 5 \mathrm{~m} \times 0.26 \mathrm{~m})$ of the concrete pavement middle is meshed by tetrahedral elements, as shown in Fig. $4 \mathrm{a}$. The geometries of random aggregates are also generated independently in the area of $3 \mathrm{~m} \times 5 \mathrm{~m} \times 0.26 \mathrm{~m}$. Then, the body-centred coordinates of each element in Fig. 4a are judged to be within the geometric range of each aggregate. If the body-centred coordinates are in the range of aggregate geometries, the tetrahedral elements are labelled as aggregate elements, as shown in Fig. 4b. The remaining elements are labelled as mortar elements. The concrete pavement model with aggregates is illustrated in Fig. 4c.

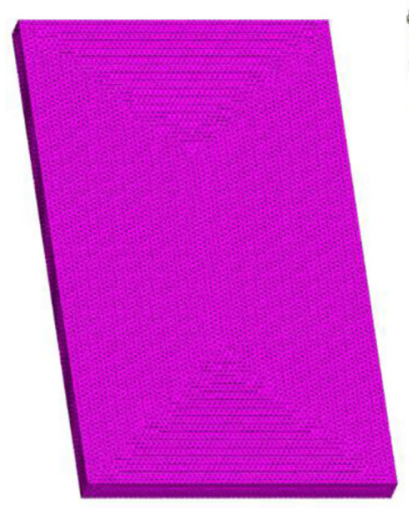

(a) Tetrahedral element model

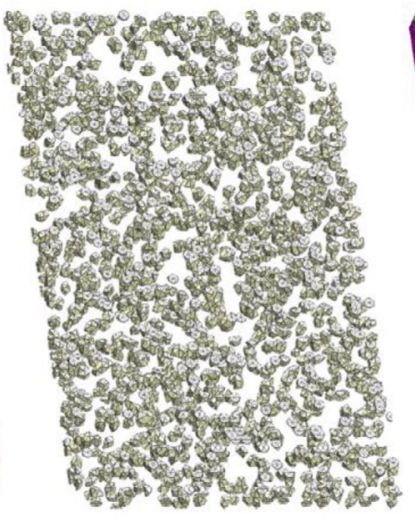

(b) Aggregate model

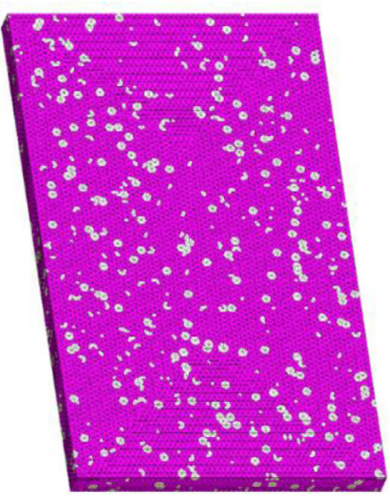

(c) Concrete pavement model

Fig. 4. Process of concrete pavement modelling. 
Table 1

Constitutive parameters of block elements.

\begin{tabular}{llll}
\hline & Density/ kg.m & Elastic modulus/ GPa & Poisson's ratio \\
\hline Hammer & 7850 & 200 & 0.25 \\
Concrete & 2400 & $3.1 \mathrm{e} 10$ & 0.2 \\
Aggregate & 2400 & 60 & 0.2 \\
Mortar & 1900 & 20 & 0.2 \\
Road base & 2410 & $1.5 \mathrm{e} 9$ & 0.25 \\
Earth base & 1700 & $40 \mathrm{e} 6$ & 0.4 \\
\hline
\end{tabular}

\subsection{Numerical parameters}

In this study, a normal contact element is used to deal with the interaction between the drop hammer and the concrete pavement. The impact cracking process of the concrete pavement structure is simulated by the fracture of the contact element. The interfacial transition zone (ITZ) of concrete mortar and aggregate is characterized by a contact element with ITZ parameters. The cracking process of mortar is calculated using a contact element with the mortar properties. The damage fracture criterion with consideration of the concrete fracture energy is also applied. The continuum element parameters of the pavement structure and the drop hammer are listed in Table 1, [21] and the contact element parameters of the entire impact system are listed in Table 2.

\subsection{Simulation scheme}

In the simulation, the elastic deformation and force of the concrete pavement, subgrade, soil foundation, drop hammer and concrete aggregate are analysed via the continuous element method. The impact cracking process of the concrete pavement is simulated via the discontinuous element method. To achieve a higher calculation efficiency and superior impact cracking modelling performance, the models of the concrete pavement structure are optimized. For the pavement models that are meshed by hexahedral elements, triangular prism elements and tetrahedral elements and the model that includes aggregates, the middles are impacted by drop hammers and the initial velocities of the drop hammers are $3 \mathrm{~m} / \mathrm{s}$. To investigate the influence of the impact location on the cracking mechanism, the impact cracking processes of the pavement middle, corner, longitudinal edge middle and transverse edge middle are simulated based on the optimized model. To investigate the influence of the impact velocity on the cracking mechanism, concrete cracking processes under various impact loadings are also simulated; the initial impact velocities of the drop hammer are $2 \mathrm{~m} / \mathrm{s}, 2.5 \mathrm{~m} / \mathrm{s}$, $3 \mathrm{~m} / \mathrm{s}$ and $3.5 \mathrm{~m} / \mathrm{s}$.

\section{Simulation results}

To intuitively evaluate the cracking effect of the concrete pavement under impact loading, the crack surface morphologies on the top, inner and bottom of the concrete pavement are analysed. For the quantitative evaluation of the concrete fracture degree, the number of contact elements that broke inside the concrete pavement is counted. The fracture degree is calculated as the ratio of the number of broken contact elements and the total number of contact elements, which is the index that indicates the degree of concrete impact cracking. The impact force during the impact process is obtained by measuring the contact force between the hammerhead and the pavement surface. Finally, the impact cracking mechanism of the concrete pavement is analysed by comparing the fracture degree and the impact force.

\subsection{Simulation results under various models}

To effectively simulate the impact cracking process of a large-scale pavement structure, the $3 \mathrm{~m} \times 5 \mathrm{~m} \times 0.26 \mathrm{~m}$ region in the pavement middle is selected as the focus of this study. The middles of pavement models that have been meshed by various shape elements are impact by a drop hammer with a velocity of $3 \mathrm{~m} / \mathrm{s}$, and the influence of the element shape on the concrete impact cracking mechanism is analysed. The effect of three-dimensional aggregates on the crack propagation paths is also discussed. In addition, the calculation efficiencies of the models are compared, and the numerical model is optimized.

\subsubsection{Crack distribution on the pavement surface}

For the models with the three element types, the crack distributions of the pavement top and bottom are shown in Fig. 5a-c. The bottom of the concrete pavement forms closed quadrangle cracks, which correspond to the impact positions of four hammerheads. In contrast, for the model that is meshed by hexahedral elements, two main cracks are generated on the pavement top, which are parallel to the pavement transverse axis, and multiple cracks appear on the pavement bottom, which are perpendicular to each other. For the model that is meshed by triangular prism elements, only few cracks form on the pavement top, and multiple symmetrical cracks appear on the pavement bottom. For the model that is meshed by tetrahedral elements, the cracks appear on the impact positions between the hammerheads and the pavement surface; moreover, the cracks on the pavement bottom exhibit symmetric bifurcation propagation. In addition, three-dimensional aggregates are generated based on the model that is meshed by tetrahedral elements. The crack distribution of the pavement surface is shown in Fig. 5d. The surface cracks are similar to those in Fig. 5c; however, there are slightly fewer cracks on the pavement top compared to the tetrahedral model without aggregates. Moreover, the bottom cracks propagate along the concrete aggregates, which follow more random extension paths. Under multi-head impact loading, the length and number of surface cracks in the pavement model that is meshed by hexahedral elements are larger compared to the model that is meshed by triangular prism elements, followed by the model that is meshed by tetrahedral elements. Moreover, the crack path randomness of the model with aggregates is higher than that of the model without aggregates.

\subsubsection{Crack surface morphology of the pavement inside}

To investigate the crack propagation of concrete pavement in threedimensional space, the crack surfaces inside concrete pavement are shown in Fig. 6. The crack surfaces of various models exhibit approximately symmetrical distributions; moreover, the lengths and areas of crack surfaces on the pavement bottom are larger than those on the upper portion. For the hexahedral meshing model, multiple crack surfaces are parallel to the longitudinal and transverse axes of the pavement, which are across and perpendicular to each other. For the model that is meshed by triangular prism elements, the crack surfaces exhibit a

Table 2

Constitutive parameters of the contact elements.

\begin{tabular}{|c|c|c|c|c|c|c|c|}
\hline & $\begin{array}{l}\text { Normal stiffness/ } \\
\text { Pa.m }\end{array}$ & $\begin{array}{l}\text { Tangential stiffness/ } \\
\text { Pa.m }{ }^{-1}\end{array}$ & Cohesion/ $\mathrm{MPa}$ & $\begin{array}{l}\text { Internal friction } \\
\text { angle } /^{\circ}\end{array}$ & $\begin{array}{l}\text { Tensile strength/ } \\
\mathrm{MPa}\end{array}$ & $\begin{array}{l}\text { Shear fracture } \\
\text { energy/ Pa.m }\end{array}$ & $\begin{array}{l}\text { Tensile fracture } \\
\text { energy/ Pa.m }\end{array}$ \\
\hline Mortar & $2.8 \mathrm{e} 11$ & $2.8 \mathrm{e} 11$ & 6.6 & 54.9 & 5 & 150 & 150 \\
\hline ITZ & $1.4 \mathrm{e} 11$ & $1.4 \mathrm{e} 11$ & 3 & 54.9 & 3 & 150 & 150 \\
\hline
\end{tabular}



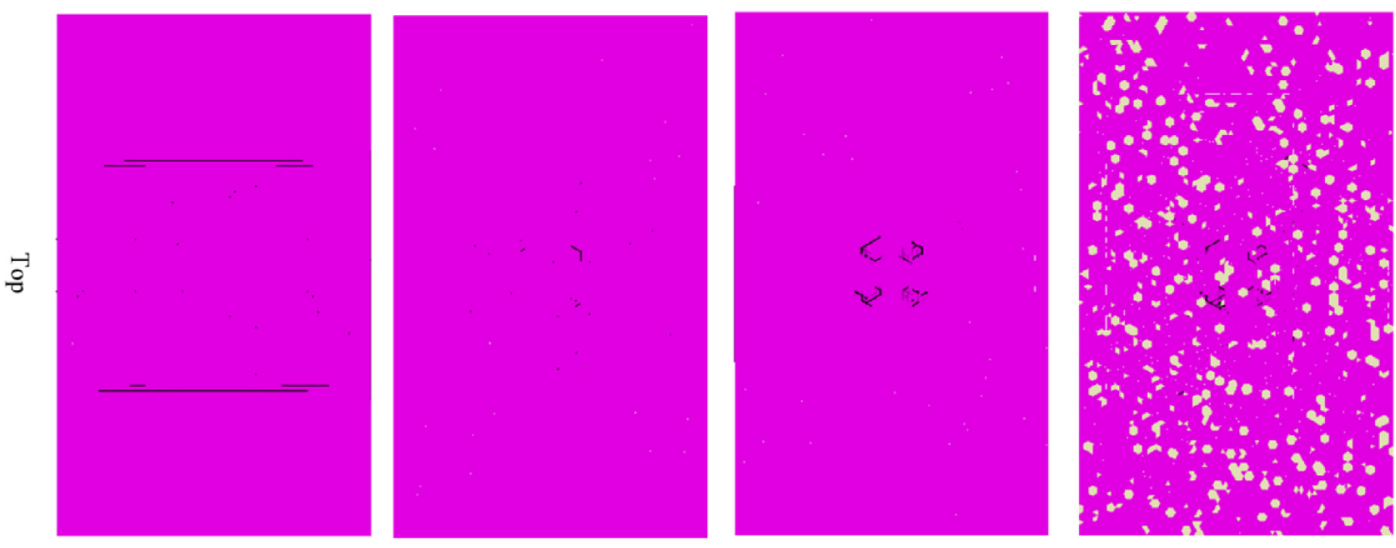

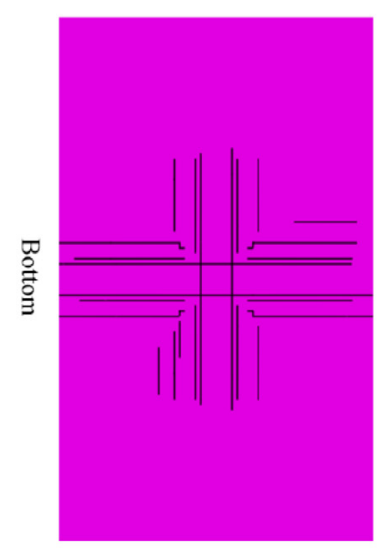

(a)Hexahedral element

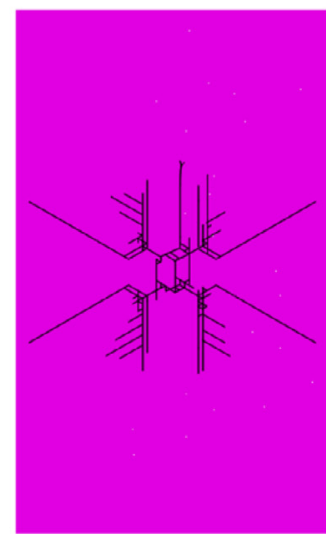

(b)Triangular prism element

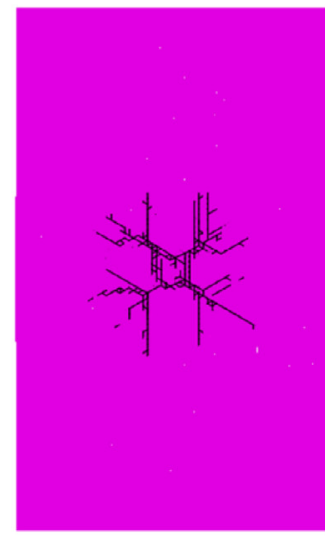

(c)Tetrahedral element

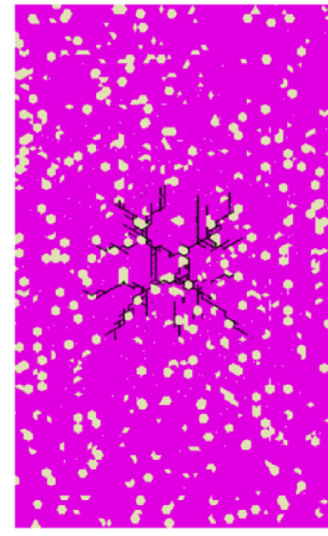

(d)Tetrahedral element with aggregate

Fig. 5. Top and bottom crack distributions of concrete pavement models.

symmetrical distribution according to the four hammerhead positions and the pavement long axis. For the tetrahedral meshing model, the crack surfaces basically present a symmetrical distribution; however, the lengths of the crack surfaces are substantially smaller than those in Fig. $6 \mathrm{a}$ and b. Meanwhile, the layer crack surfaces are generated. For the tetrahedral meshing model with aggregates, the crack surfaces are similar to that of Fig. $6 \mathrm{c}$, and the crack surfaces propagate around the aggregates; moreover, the area of the layer crack surface is smaller than that of the surface in Fig. $6 \mathrm{c}$.

\subsubsection{Fracture degree and impact force}

To further investigate the impact cracking mechanisms of various pavement models, the fracture degree and the impact force curves in the impact process are obtained, which are plotted in Fig. 7a and b. According to Fig. 7a, the fracture degrees of various models have not increased substantially during the impact process of $0 \mathrm{~ms}-1.5 \mathrm{~ms}$; however, the variation of the fracture degrees within $1.5 \mathrm{~ms}-12 \mathrm{~ms}$ is substantial. The effective time of concrete impact cracking, the change rate of the fracture degree and the ultimate value of the fracture degree are largest for the hexahedral meshing model, followed by the triangular prism meshing model and the tetrahedral meshing model, and these values are smaller for the tetrahedral meshing model without aggregates than for the model with aggregates. According to Fig. 7b, the impact forces vary according to a half sine curve; however, the change rate of the impact force in the growth stage is higher than in the attenuation stage. The impact force maximum and the change rate of the impact force curve are largest for the hexahedral meshing model, followed by the triangular prism meshing model and the tetrahedral meshing model; the values for the tetrahedral meshing model without aggregates are similar to those of the model with aggregates. Compared with Fig. $7 \mathrm{a}$ and $\mathrm{b}$, the impact forces increase during the process in the range of $0 \mathrm{~ms}-1.5 \mathrm{~ms}$, whereas the fracture degrees of the concrete

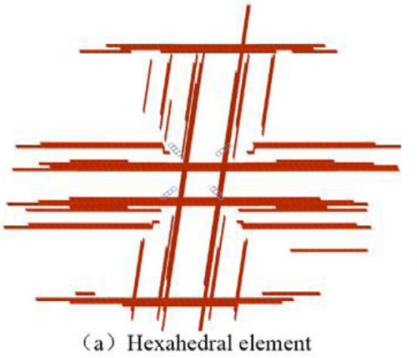

(a) Hexahedral element

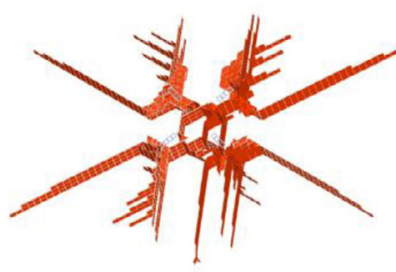

(b) Triangular prism element

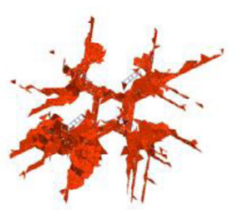

(c) Tetrahedral element

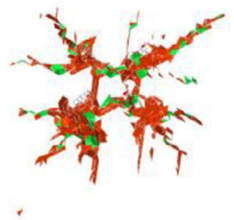

(d) Tetrahedral element with aggregate

Fig. 6. Crack surfaces of concrete pavement models. 


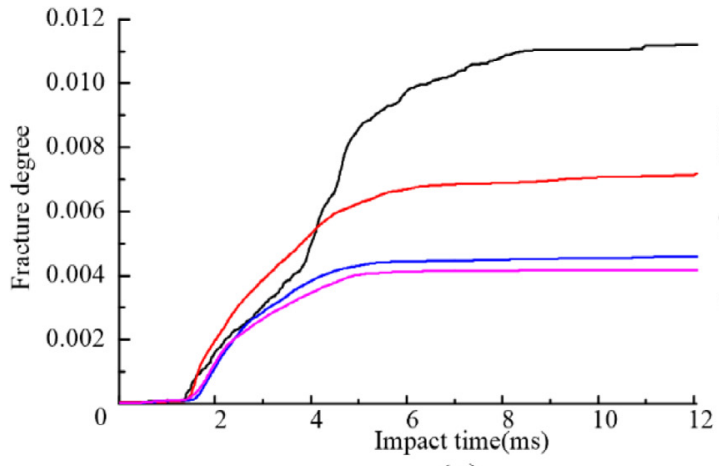

(a)

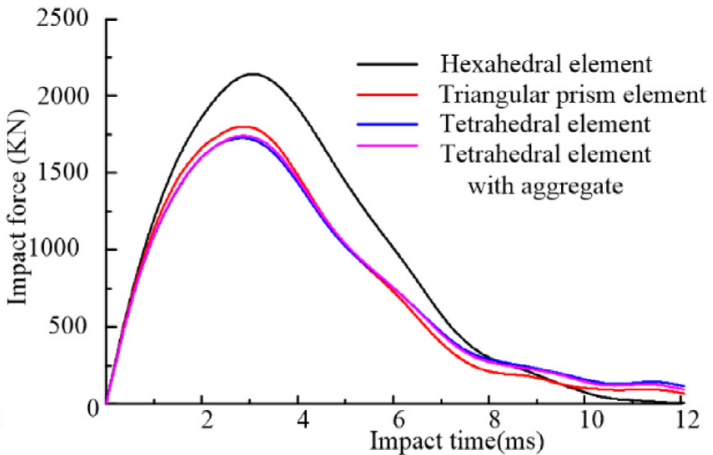

(b)

Fig. 7. Simulation curves under various concrete pavement models: (a) The fracture degree and (b) the impact force.

pavement do not change substantially. In the range of $1.5 \mathrm{~ms}-3 \mathrm{~ms}$, the impact forces continuously increase to the peak value, and the fracture degrees of the concrete pavement also increase. In the range of $3 \mathrm{~ms}-12 \mathrm{~ms}$, the impact forces begin to gradually decrease, whereas the fracture degrees still increase until gradually reaching a steady state.

\subsubsection{Discussion of various models}

According to Fig. 5, the number of pavement bottom cracks is substantially larger than the number of pavement top cracks. That may be because the concrete pavement top is partially crushed under multihead impact loading; however, bending and cracking firstly occur on the bottom, and then the cracks propagate from the bottom to the top. According to Fig. 6, the element interfaces provide potential paths on crack surfaces; hence, vertical crack surfaces occur in the models that are meshed by hexahedral and triangular prism elements. The randomness of the tetrahedral element interfaces is greater than those of the hexahedral and triangular prism element interfaces; hence, the propagation paths of crack surfaces are more random for the tetrahedral element model, and the length of the crack surface is smaller. Moreover, horizontal-layer crack surfaces also appear inside the concrete pavement. Since the crack surfaces propagate around the aggregates and the concrete aggregates enhance the crack resistance of concrete, the area of the layer crack surface for the model that includes aggregates is smaller than that of the model without aggregates.

Compared with the fracture degree and impact force in Fig. 7, since concrete cracking need absorb energy, the fracture degrees do not change substantially in the range of $0 \mathrm{~ms}-1.5 \mathrm{~ms}$, although the impact forces continuously increase. In the range of $1.5 \mathrm{~ms}-3 \mathrm{~ms}$, the impact forces continually increase to the peak value, and the concrete continuously absorbs energy; hence, the fracture degrees are also increasing. This may be because the hammer begins to rebound after the impact force reaches its peak value, and the concrete remains in the loading stage until the hammer separates from the concrete pavement. Therefore, the impact forces begin to gradually decrease in the range of $3 \mathrm{~ms}-12 \mathrm{~ms}$, but the fracture degrees still increase until gradually reaching a steady state.

Overall, the tetrahedral meshing model generates the most random propagation paths of impact crack surfaces. Moreover, concrete aggregates can change the propagation paths, which enhances the randomness of the propagation paths. Furthermore, in the simulation of the impact cracking process in a large-scale pavement structure, the calculation time is an important factor. Ten thousand iteration steps of various models are conducted by the same computer. Then, the calculation efficiencies of the models are compared; the results are presented in Fig. 8. The calculation time of the tetrahedral meshing model is longer than that of the triangular prism meshing model, followed by the hexahedral meshing model. The calculation time of the tetrahedral meshing model with aggregates is smaller than that of the model without aggregates. Therefore, the tetrahedral meshing model with aggregates not only yields superior impact cracking results for concrete

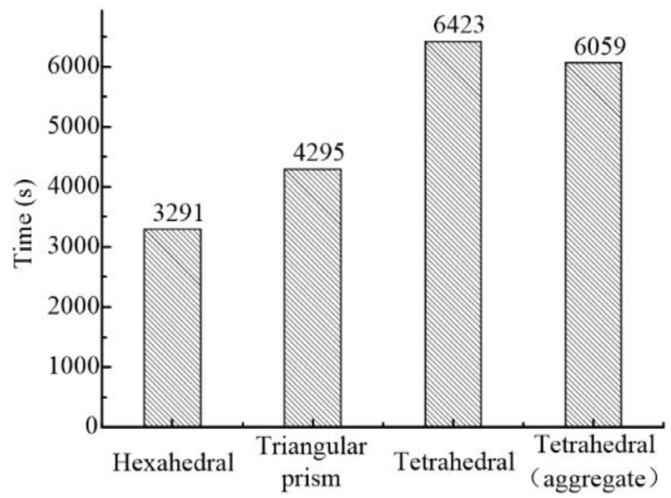

Fig. 8. Calculation efficiencies of various concrete pavement models.

pavement but also has a higher calculation efficiency. The optimized model is utilized to further investigate the impact cracking mechanism of concrete pavement.

\subsection{Simulation results under various impact conditions}

In a project site, the effects of the drop hammer on the concrete pavement depend on the location, and the cracking results differ among locations. The pavement cracking effects also depend on the impact velocity. Therefore, the influences of the impact location and velocity on the cracking mechanism are investigated with the optimized numerical model. The cracking process under impact loading is simulated using various impact locations, such as the pavement middle, the pavement corner, the middle of the pavement longitudinal axis edge and the pavement transverse axis edge middle. Moreover, simulations of the impact cracking processes are also conducted under various impact velocities, such as $2 \mathrm{~m} / \mathrm{s}, 2.5 \mathrm{~m} / \mathrm{s}, 3 \mathrm{~m} / \mathrm{s}$, and $3.5 \mathrm{~m} / \mathrm{s}$. To conveniently describe the effects of four hammerheads on pavement cracking, the hammerhead location in the upper-left corner of the drop hammer bottom is denoted as position 1 , the hammerhead location in the upperright corner is denoted as position 2 , the hammerhead location in the lower-right corner is denoted as position 3 , and the hammerhead location in the lower-left corner is denoted as position 4 .

\subsubsection{Crack surface morphology of concrete pavement}

Under various impact locations and velocities, the crack surface morphologies inside concrete pavement are shown in Fig. 9. The concrete cracking degrees for various impact locations increase as the impact velocity increases.

Under impact loading velocities of $2 \mathrm{~m} / \mathrm{s}$ and $2.5 \mathrm{~m} / \mathrm{s}$, the impact cracking of concrete mainly occurs on the pavement bottom. The generated closed quadrangle crack surfaces correspond to the insides of the four hammerheads. Moreover, the crack surfaces propagate out along 


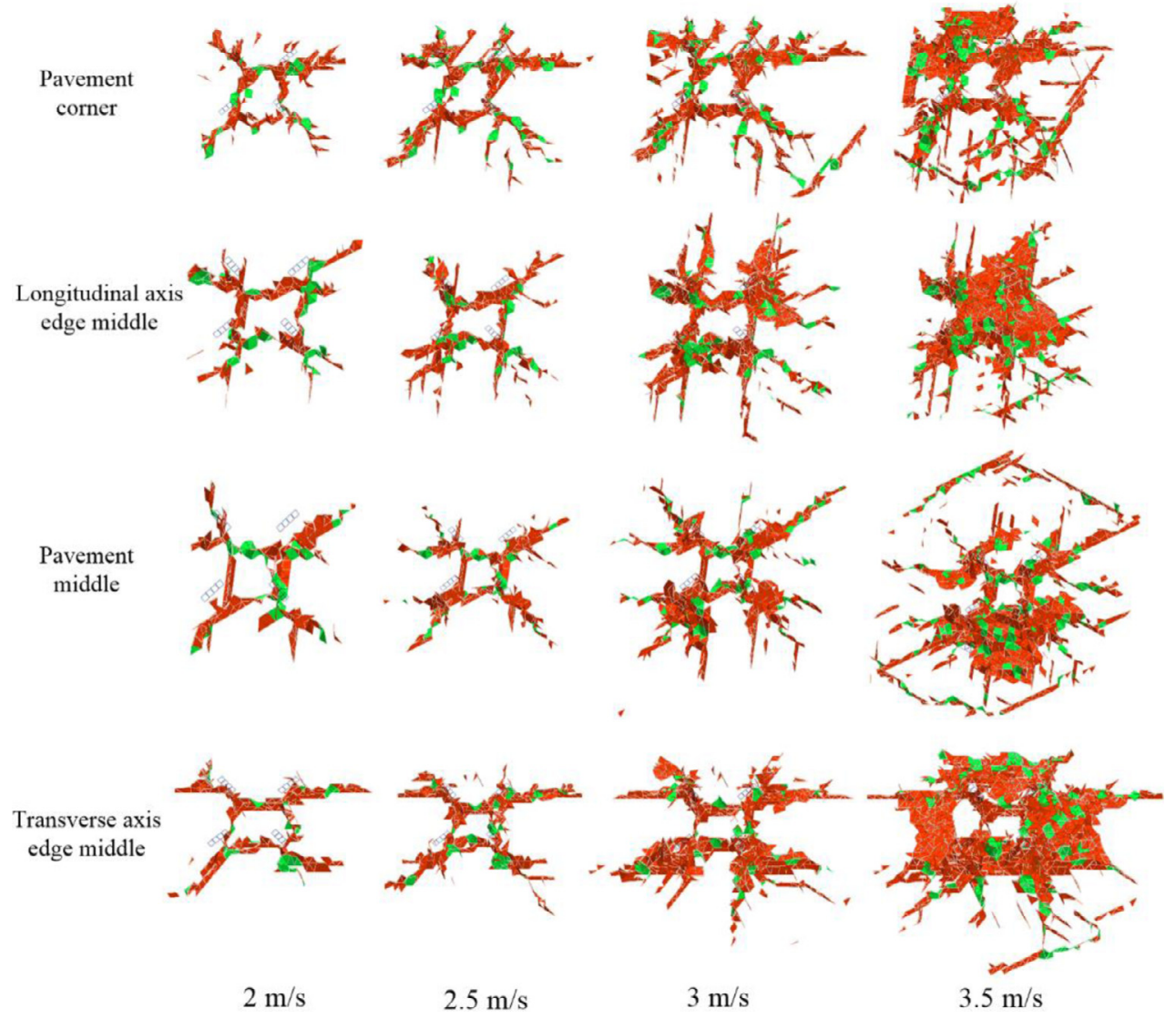

Fig. 9. Fracture surfaces of various impact locations and velocities.

the long axis of the rectangular hammerheads. The morphologies of the crack surfaces are basically similar among impact locations; however, the slightly differences are that the crack surface morphology in the pavement middle is more symmetric than that in the edge middle of the pavement, followed by that in the pavement corner. In contrast to the crack surfaces of $2 \mathrm{~m} / \mathrm{s}$ impact velocity, the crack surfaces of $2.5 \mathrm{~m} / \mathrm{s}$ impact velocity easily propagate to the pavement top, and the bifurcation propagation of the crack surface along the hammerhead axis is readily observed.

Under the impact loading velocity of $3 \mathrm{~m} / \mathrm{s}$, the lengths of the crack surfaces along the hammerhead axis increase substantially, and horizontal-layer crack surfaces begin to form. Annular crack surfaces are also generated. The differences in the crack surfaces among the impact locations are that the pavement corner impact causes a local annular crack. More specifically, for the impact of the pavement corner, the length of the crack surface near the corner hammerhead (position 1) is smaller than those of the pavement edge hammerheads (positions 2 and 4), which are smaller than that of the hammerhead (position 3) of the pavement inside. Moreover, for the impact locations of the pavement edge middle, near the hammerheads (position 1 and 4) of the pavement longitudinal axis edge middle and the hammerheads (position 1 and 2) of the pavement transverse axis edge middle, the lengths of crack surfaces are smaller than those of the hammerheads of the pavement inside. Meanwhile, there exist multiple crack surfaces, which are parallel to the longitudinal and transverse axes of the pavement. For the impact locations of the pavement middle, the main crack surfaces are symmetric and bifurcated.

Under the impact loading velocity of $3.5 \mathrm{~m} / \mathrm{s}$, readily observable layer crack surfaces and annular crack surfaces begin to occur. The crack surface morphologies differ substantially among impact locations. For the impact location of a pavement corner, position 1 of the corner hammerhead generates more layer crack surfaces, and the position 3 of the pavement inside hammerhead generates more annular crack surfaces. With respect to the impact locations of the pavement edge middle, the layer crack area in the pavement transverse edge middle is larger than that in the longitudinal edge middle. In the impact locations of the pavement middle, two symmetrical annular crack surfaces occur in the pavement top, which are relative to the pavement transverse axis.

\subsubsection{Concrete pavement fracture degree}

The concrete pavement is impacted by a drop hammer at various locations with various initial velocities, and the fracture degree variation of the concrete pavement is monitored during the impact process. For the quantitative evaluation of the pavement cracking degree, the final fracture degree values under various conditions are calculated and analysed. The time history curves and statistical results of the fracture degree are presented in Fig. 10. The fracture degrees during the impact process initially exhibit slow growth and subsequently increase rapidly until finally stabilizing. The variation stages are as follows:

In the initial slow growth phase, the change tendencies of the fracture degree at various impact locations are approximately the same; however, the duration of this stage decreases as the impact velocity increases. In the rapid increase stage, the change rates of the fracture degree curves increase as the impact speed increases. Under the impact loading velocities of $2 \mathrm{~m} / \mathrm{s}$ and $2.5 \mathrm{~m} / \mathrm{s}$, as shown in Fig. 10a and b, the change rates of the fracture degree in the pavement corner are larger than those in the pavement middle, which are larger than those at the pavement edge. Moreover, the change rates in the longitudinal edge middle are similar to those in the transverse axis middle. Under the impact loading velocity of $3 \mathrm{~m} / \mathrm{s}$, as shown in Fig. 10c, the change rate in the pavement middle is larger than that in the pavement corner, which is larger than that at the pavement edge in the range of $1.5 \mathrm{~ms}-3 \mathrm{~ms}$. However, the change rate at the pavement edge in the range of $3 \mathrm{~ms}-5 \mathrm{~ms}$ is larger than those at the pavement middle and 


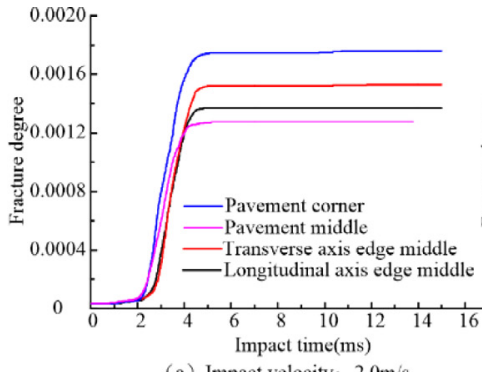

(a) Impact velocity: $2.0 \mathrm{~m} / \mathrm{s}$

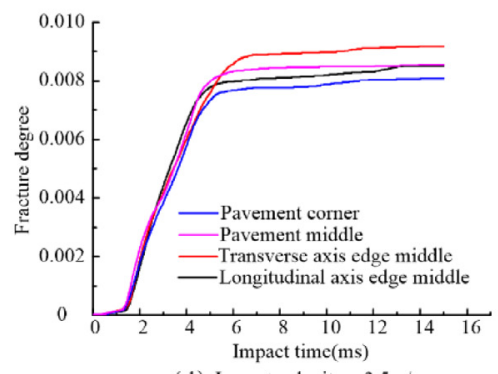

(d) Impact velocity: $3.5 \mathrm{~m} / \mathrm{s}$

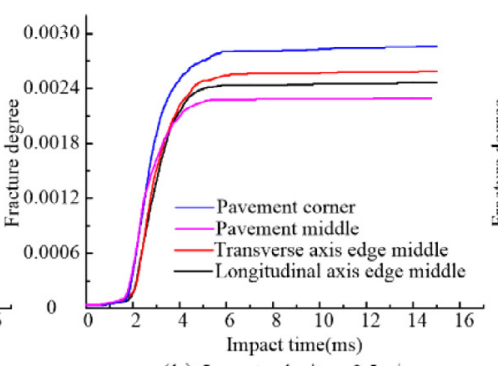

(b) Impact velocity: $2.5 \mathrm{~m} / \mathrm{s}$

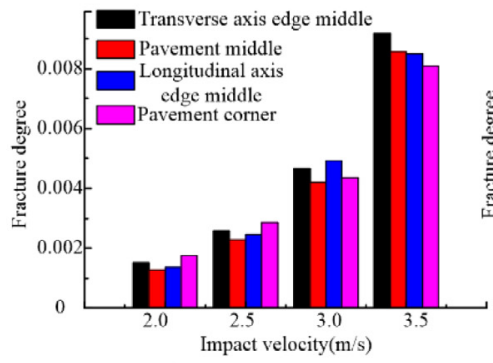

(e) Peak value of fracture degree
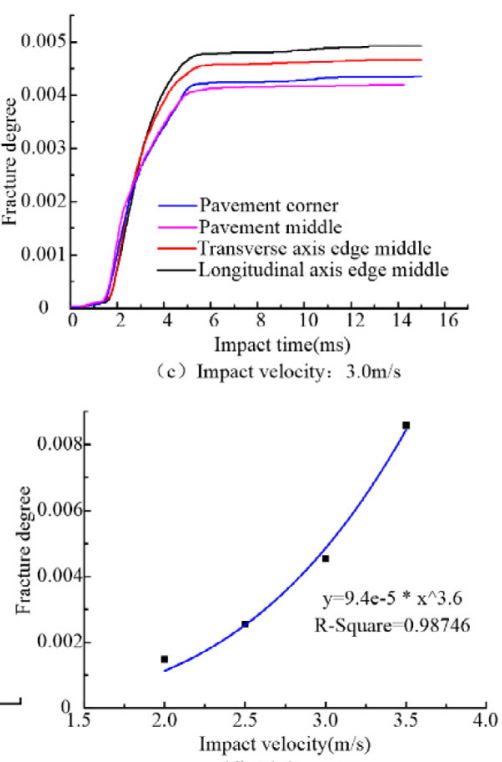

(f) Fitting curve

Fig. 10. Fracture degrees under various impact locations and velocities.

corner. Under the impact loading velocity of $3.5 \mathrm{~m} / \mathrm{s}$, as shown in Fig. 10d, the change rate in the pavement corner is minimal. Moreover, the change rate in the pavement middle in the range of $1.5 \mathrm{~ms}-2.5 \mathrm{~ms}$ is larger than at the pavement edges, whereas the change rate in the longitudinal edge middle is maximal in the range of $3 \mathrm{~ms}-5 \mathrm{~ms}$.

The stable variation stage of the fracture degree indicates that the impact cracking time increases as the impact velocity increases. Meanwhile, as shown in Fig. 10e, under the impact velocities of $2 \mathrm{~m} / \mathrm{s}$ and $2.5 \mathrm{~m} / \mathrm{s}$, the final values of the fracture degree in the pavement middle are smaller than those in longitudinal edge middle, followed by those in the transverse edge middle and in the pavement corner. Under the impact velocity of $3 \mathrm{~m} / \mathrm{s}$, the final value in the pavement middle is smaller than that in the pavement corner, followed by those in the transverse edge middle and in the longitudinal edge middle. Furthermore, under the impact velocity of $3.5 \mathrm{~m} / \mathrm{s}$, the final value of the fracture degree in the pavement corner is smaller than that in the longitudinal edge middle, followed by those in the pavement middle and in the transverse edge middle. Overall, the fracture degrees of the concrete pavement increase as the impact velocity increases. To further investigate the variation law of the fracture degree, the fracture degrees with various impact locations are averaged, and the averaged fracture degrees under various impact velocities are fitted, as plotted in Fig. $10 \mathrm{f}$. As the impact velocity increases, the averaged fracture degrees follow a power function, and the correlation coefficient is 0.98746 .

\subsubsection{Impact forces under various conditions}

Under various impact locations and impact velocities, the impact force variation of the concrete pavement during the impact process is monitored. For the quantitative evaluation of the pavement impact force, the final impact force peaks under various conditions are identified and analysed. The time history curves and statistical results of the impact forces are presented in Fig. 11.

The impact force curves show an approximate half sinusoidal change, which initially increases and subsequently attenuates. As the impact velocity increases, the curve change rate increases, as does the impact force peak. Under the same impact velocity, the increase stages of the impact force curves for various impact locations are similar; however, substantial differences are observed in the attenuate stage. Moreover, the impact force peaks in the concrete pavement middle are minimal, whereas the impact force peaks in the pavement corner and edge are approximate. According to Fig. 11e, as the impact velocity increases, the impact force peaks in the pavement corner and the transverse axis edge middle gradually become large relative to the longitudinal axis edge middle. To further investigate the variation law of the impact force, the impact force peaks in various impact locations are averaged, and the averaged impact force peaks under the various impact velocities are fitted, as shown in Fig. 11f, which linearly change as the impact velocity increases; the correlation coefficient is 0.99996 .

To further analyse the impact cracking mechanism of concrete pavement, in combination with Figs. 10 and 11, the fracture degrees and impact force peaks under various impact conditions are compared, as shown in Fig. 12. The larger the impact velocity, the larger the impact force peaks and the fracture degrees of the concrete pavement. The differences in the fracture degrees among impact locations are substantial under the same impact velocity. There are also substantial variations in the fracture degrees as the impact velocity increases. Although the impact force peaks increase as the impact velocity increases, only the impact force of the pavement middle is substantially smaller compared to the other impact locations; the variations of the impact force peaks in the pavement corner and edges are similar. In addition, the impact force peaks linearly change as the impact velocity increases; however, the final fracture degrees vary according to a power function. Moreover, the weight of the impact velocity is larger than that of the impact location.

\section{Verification}

\subsection{Field test scheme}

To evaluate the accuracy of the simulation results of concrete pavement impact cracking, impact testing of concrete pavement is conducted, as shown in Fig. 13a. This field test relies on the repair project of the urban road in Xinyang City, Henan Province, China. The pavement middle, pavement edge middle and pavement corner are impacted by a drop hammer, and the cracks on the pavement surface are highlighted with black permanent marker. Then, the in-site crack distribution of the pavement surface is compared with the crack surfaces from the simulation. Moreover, the pavement middles are respectively subjected to one and two impacts of the drop hammer to evaluate the effect of the impact velocity on the cracking. Since the in-site impact test only yields the surface crack distribution of the concrete pavement, the distribution and morphology of the pavement internal crack surfaces 


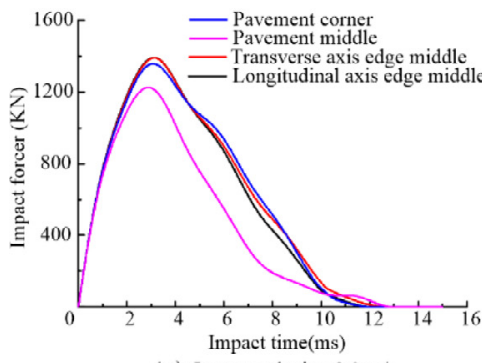

(a) Impact velocity: $2.0 \mathrm{~m} / \mathrm{s}$

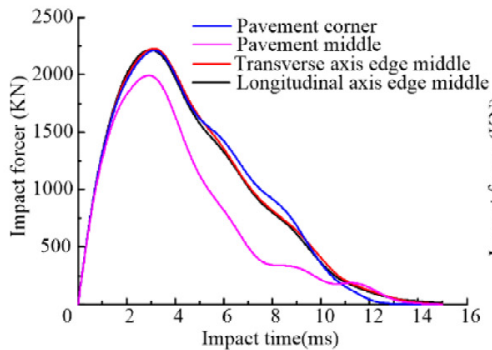

(d) Impact velocity: $3.5 \mathrm{~m} / \mathrm{s}$

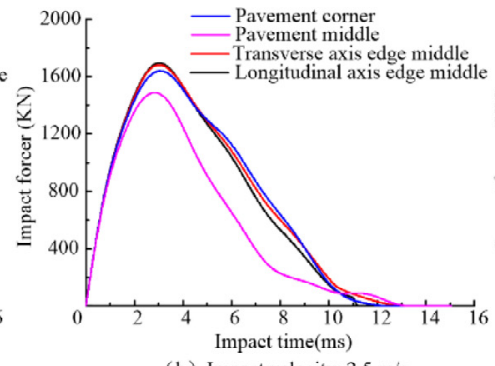

(b) Impact velocity: $2.5 \mathrm{~m} / \mathrm{s}$

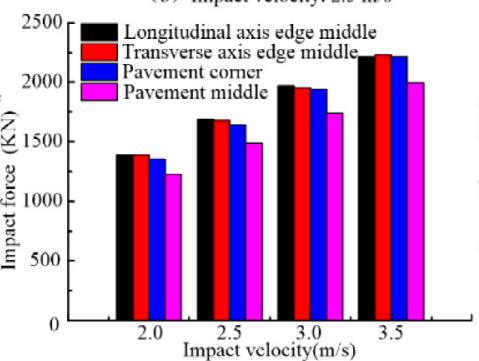

(e) Peak values of impact force

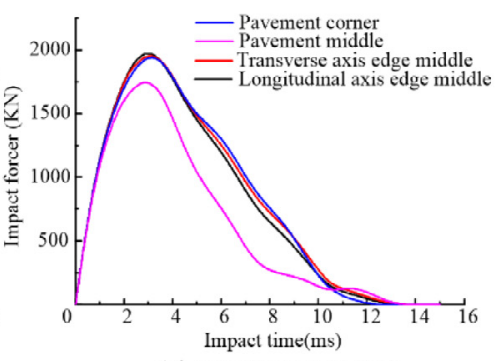

(c) Impact velocity: $3.0 \mathrm{~m} / \mathrm{s}$

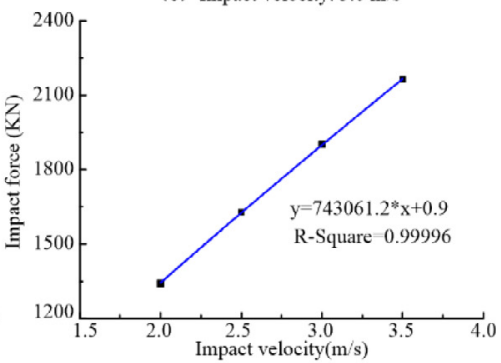

(f) Fitting curve

Fig. 11. Impact forces under various impact locations and velocities.

must be further investigated. Therefore, in-site core drilling is conducted at typical locations on the concrete pavement, as shown in Fig. 13b, which are used to evaluate the crack surface morphology that was obtained via simulation.

\subsection{Pavement crack distribution}

After the pavement middle, pavement edge middle and pavement corner have been impacted by the drop hammer, the test results are presented in Fig. 14. The contact positions between the hammerheads and the pavement surface are crushed, and approximately quadrilateral cracks along the inside of the four hammerheads are formed. Moreover, the main cracks propagate along the long axis of the rectangular hammerhead. The pavement corner easily generates annular cracks, and cracks that are parallel to pavement axis easily form in the pavement corner and edge. The cracks in the pavement middle are relatively symmetric. For various impact locations, the impact cracking results from the simulation are also presented in Fig. 14, which mostly accord with the results of the in-site tests.

\subsection{In-site core drilling}

Core drilling is conducted at eight typical locations of the concrete pavement, which are identified by referring to the surface crack distribution after impact cracking of the concrete pavement, as illustrated in Fig. 15. Core drillings No. 1, 2, 3 and 8 are located in the concrete pavement middle. Core drillings No. 4 and 5 are located in the concrete pavement corner. Core drillings No. 6 and 7 are located in the concrete pavement edge middle. More concretely, core drillings No. 3, 1, 7 and 4 locate on the tension cracks outward of the rectangular hammerhead axis, and the distances relative to the impact positions are from near to far. Core drillings No. 2 and 6 are located between the insides of two hammerheads. Moreover, core drilling No. 8 is located near impact positions of hammerheads. Core drilling No. 5 is located on annular cracks outside of two impact positions. Furthermore, after core drilling, the pavement hole distribution is shown in Fig. 15.

After core drilling, the fracture morphologies of the core samples are shown in Fig. 16, a bevelled crack surface appears at the bottom of core sample No. 1. Core sample No. 2 has a vertical crack surface in the sample bottom. A bevelled crack surface appears in the middle of core

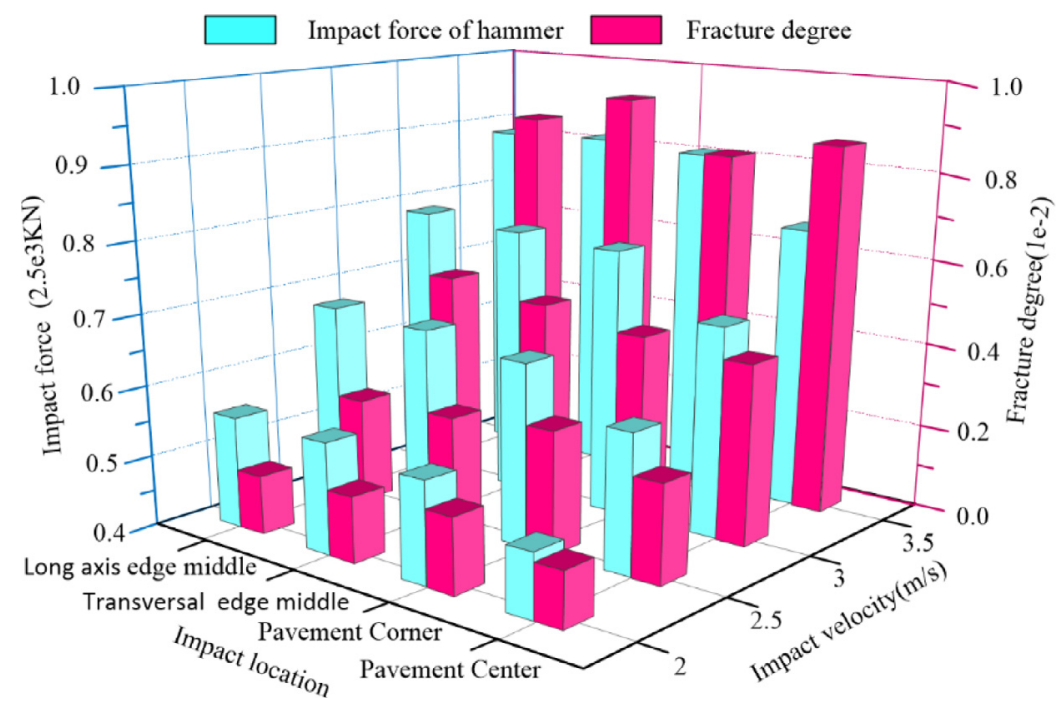

Fig. 12. Fracture degree and impact force under various impact conditions. 


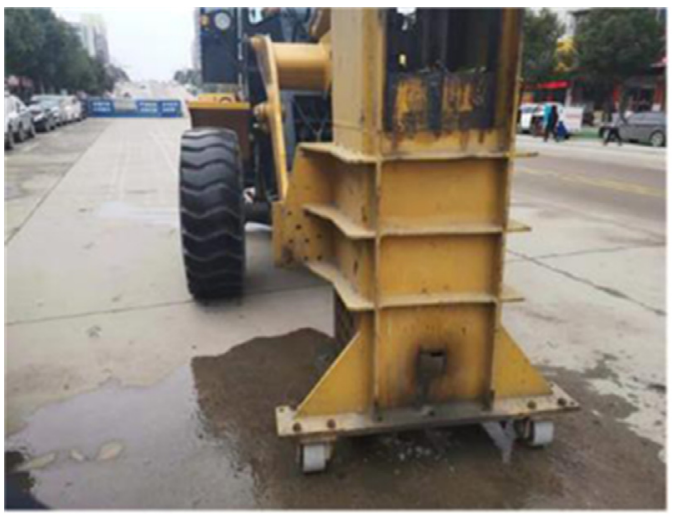

(a) Impact test

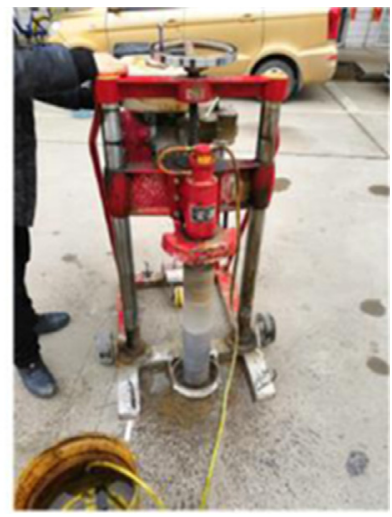

(b) Drilling core

Fig. 13. In-site impact test and core drilling of concrete pavement.

sample No. 3, and a vertical crack forms from the bottom to up. There is a through crack from the bottom to the top in core sample No. 4. A bevelled crack surface appears in the lower part of core sample No. 5, and a layer crack surface occurs in the upper part. Core sample No. 6 also shows a vertical crack. A bevelled crack surface appears at the bottom of core sample No. 7, and a vertical crack penetrates the surface. Partial stratification cracking occurs in the upper part of core sample No. 8, and two bevelled crack surfaces appear in the sample middle.

The bevelled crack surface appears in core samples No. 1, 3, 5, 7 and 8; hence, the concrete pavement will undergo compression-shear cracking under the impact loading. Core samples No. 3 and 8 are near the impact positions of the hammer, and the compression-shear crack surface occurs in the middle of each core sample. However, core sample No. 1, 5 and 7 are located far from the impact positions, and the compression-shear crack surface occurs at the core sample bottom. Therefore, the compression-shear crack surface is generated from the top to the bottom and extends outward from the impacted position. Core sample No. 3 produces a compression-shear crack surface under one impact loading, and core sample No. 8 produces two compressionshear crack surfaces under two impact loadings; hence, the higher the impact energy, the more severe the compression-shear cracking of the concrete pavement.

Core samples No. 2 and 6 are located in the inner sides of two hammerheads, which both generates vertical crack surfaces; hence, the concrete pavement inside may generate closed quadrilateral crack surfaces along the four hammerhead insides. Moreover, the vertical crack surface height of core sample No. 6 is larger than that of core sample No. 2. However, the cracks do not penetrate the core sample; hence, the quadrilateral crack surfaces may expand from the concrete pavement bottom to top.

Along the long axis of the rectangular hammerhead, the core samples from near to far are No. 3, 7 and 4, which all generate vertical crack surfaces. Moreover, the vertical fracture surface height of core sample No. 3 is smaller than that of core sample No. 7, which is smaller than that of core sample No. 4. The heights indicate that the concrete pavement produces the tension crack surface along the long axis of the rectangular hammerhead, which also extends from the pavement bottom to the top.

\section{Discussion}

Due to the bending and cracking of the concrete pavement bottom under multi-head impact loading of lower velocity, the main tension crack surfaces propagate along the long axes of four rectangular hammerheads; moreover, closed quadrangular crack surfaces are formed along the insides of the four hammerheads. As the impact velocity increases, the absorbed energy for crack surface propagation increases; hence, the crack surfaces begin to propagate from the pavement bottom to the top, and the lengths of the crack surfaces become large. As the impact velocity continues to increase, compression-shear cracking
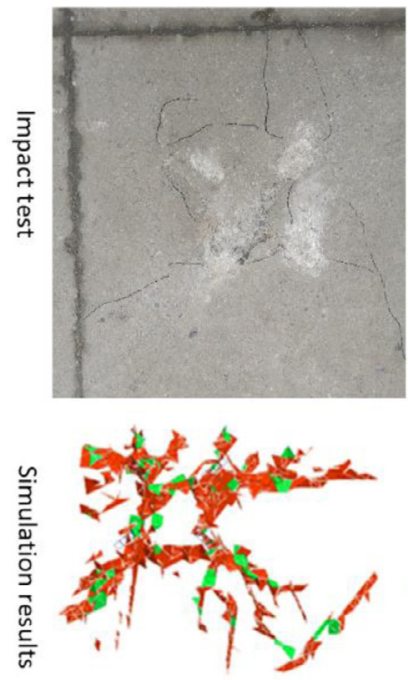

Pavement corner
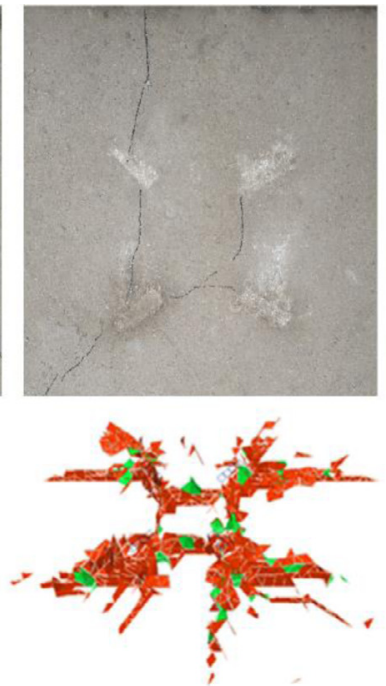

Middle of pavement edge
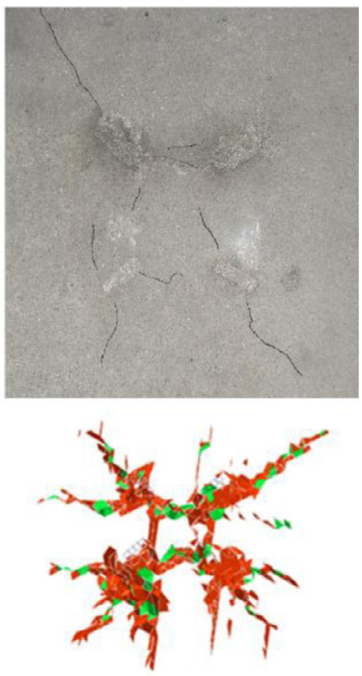

Pavement middle

Fig. 14. Results of the impact test and simulation. 


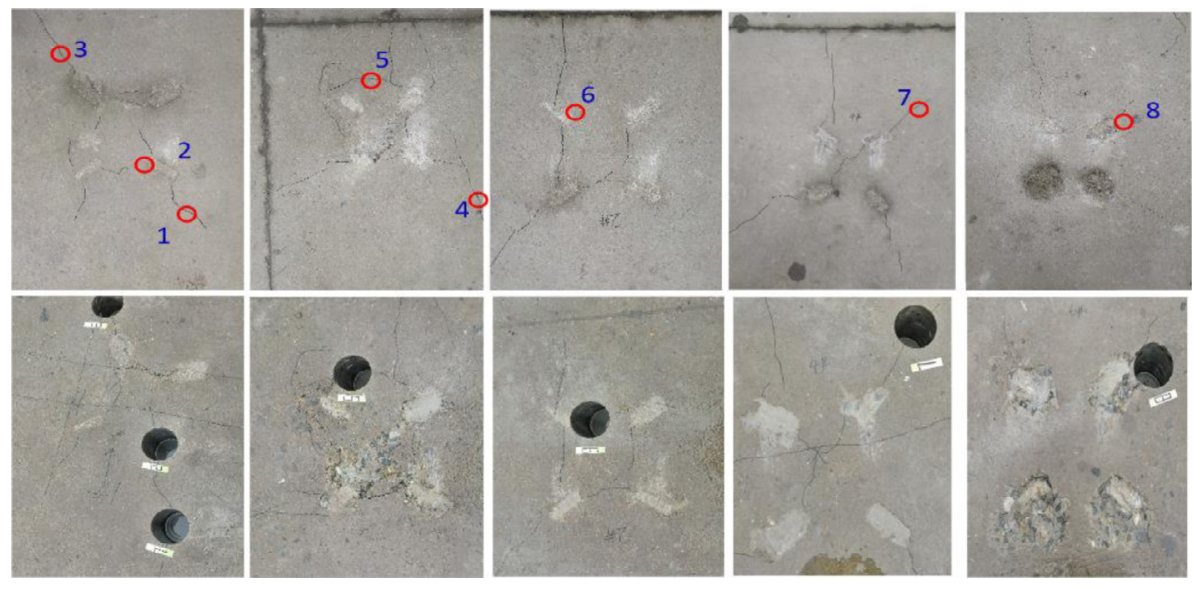

Fig. 15. Scheme and result of core drilling.

surfaces form below the contact positions between the hammerheads and the pavement surface. As the impact velocity is sufficiently large, layer tension crack surfaces form in the concrete pavement middle layer, and annular tension crack surfaces form in the pavement top.

Due to the geometrical and mechanical boundary conditions of the pavement corners and edges, the propagation of the crack surface is limited by the pavement boundary, however, the impact energy determines the final fracture degree of the concrete pavement. Therefore, when the concrete pavement is subjected to a low-velocity impact, the influence of the pavement boundary on the crack surface propagation is larger; as the impact velocity is enough large, the influence of the impact locations on the crack surface propagation is smaller. As a result, the impact force linearly changes as the impact velocity increases. However, the fracture degree of concrete pavement changes according to a power function. Moreover, the crack surface morphology in the pavement middle is more symmetric, annular crack surfaces more easily form in the pavement middle, and layer crack surfaces more easily form in the pavement corner and edges. In addition, at the impact locations of the pavement corner or edges, the crack surface lengths near the pavement boundary hammerheads are smaller than those of the pavement inside hammerheads.

As a summary, as the impact velocity increases, more energy is absorbed for concrete cracking, hence, the fracture degree increases. The geometrical and mechanical boundary conditions of the pavement limit the crack surface propagation; hence, the initial positions, propagation paths, and final morphology of the crack surfaces differ among impact locations. The impact energy determines the fracture degree of the concrete pavement; thus, the final fracture degrees for concrete pavement substantially differ among impact velocities. Regarding the effect factors of concrete pavement impact cracking, the weight of the impact velocity is larger than that of the impact location.

\section{Conclusions}

In this paper, a full-scale road 3D numerical model that includes three-dimensional random aggregates is established, and a damage fracture criterion that considers the concrete fracture energy is applied to the element interfaces of the concrete fracture area. Simulations of concrete impact cracking under various element shapes, impact locations and impact velocities are conducted via the coupled application of the continuous element method and the discontinuous element method. Furthermore, the fracture degree and the impact force are used to analyse the cracking mechanism of the concrete pavement. Finally, an impact experiment and core drilling in the field are conducted to
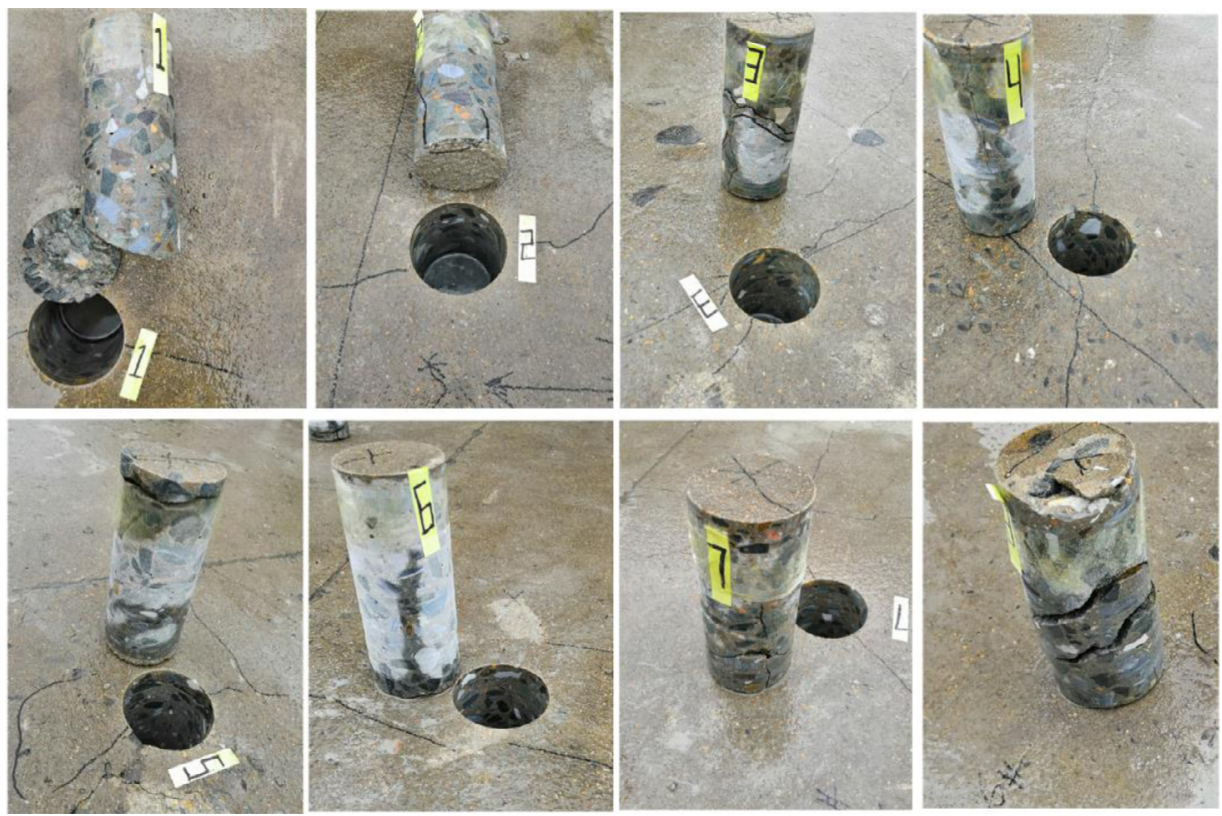

Fig. 16. Crack distributions and crack surface morphologies of the core samples. 
evaluate the simulation results. The following conclusions are obtained:

(1) Concrete pavement crushing and crack propagation can be quickly simulated via the continuum-discontinuum element method (CDEM). The simulation results accord with the results of the in-site tests. Under the multi-head impact loading, the concrete pavement model that is meshed by tetrahedral elements can generate the relatively random paths of crack surface propagation. A higher calculation efficiency and superior impact cracking performance can be realized by considering the three-dimensional random aggregates.

(2) Under the impact loading, the concrete pavement top is crushed near four hammerheads, annular crack surfaces are formed away from the impact positions, and closed quadrilateral crack surfaces are formed along the inside of four hammerheads. However, the tension crack surfaces propagate from the concrete pavement bottom to top and along the long axis of the rectangular hammerhead.

(3) The crack surfaces in the pavement edge and corner more easily propagate than those in the pavement middle. However, the crack surface morphology in the pavement middle is more symmetric. The pavement bottom only generates tension crack surfaces under lower velocity impact loading, whereas compression-shear crack surfaces and layer tensile crack surfaces are generated under higher velocity impacts. Moreover, the influence of the impact velocity on the concrete cracking is greater than that of the impact location. The impact force linearly changes as the impact velocity increases, whereas the fracture degree varies according to a power function.

\section{Acknowledgments}

This research was funded by Henan Provincial Department of Transportation (Project no. 2018J4); the National Key Research and Development Program of China (Grant No. 2018YFC1505504); and National Natural Science Foundation of China (Grant No. 51708513).

\section{Reference}

[1] Ma J, Sun S, Rui H, et al. Review on China's road construction machinery research progress:2018. China J Highway Transport 2018;31:1-164.

[2] Ceylan H, Gopalakrishnan K, Coree BJ, et al. Rehabilitation of concrete pavements utilizing rubblization: a mechanistic based approach to HMA overlay thickness design. Int J Pavement Eng 2008;9(1):45-57.

[3] Chen DH, Huang Q, Ling J. Shanghai's experience on utilizing the rubblization for jointed concrete pavement rehabilitation. J Perform Constr Facil 2008;22:398-407.

[4] Qiu X, Ling J, Wang F. Concrete pavement rehabilitation procedure using resonant rubblization technology and mechanical-empirical based overlay design. Can J Civil Eng 2013;41(1):32-9.

[5] Ge Z, Li H, Han Z, Zhang Q. Properties of cold mix asphalt mixtures with reclaimed granular aggregate from crushed PCC pavement. Constr Build Mater 2015;77:404-8.

[6] Li W, Zhang Q, Zhi Z, et al. Investigation on the fracture mechanism of homogenized micro-crack crushing technology for portland cement concrete pavement rehabilitation. AIP Adv 2019;9(7):075113.

[7] Chen Y, May IM. Reinforced concrete members under drop-weight impacts. Proc Inst Civil Eng-Struct Build 2009;162(1):45-56.

[8] Dey V, Bonakdar A, Mobasher B. Low-velocity flexural impact response of fiberreinforced aerated concrete. Cement Concrete Compos 2014;49:100-10.

[9] Yoo D-Y, Yoon Y-S. Influence of steel fibers and fiber-reinforced polymers on the impact resistance of one-way concrete slabs. J Compos Mater 2014;48(6):695-706.

[10] Zhang W, Chen S, Liu Y. Effect of weight and drop height of hammer on the flexural impact performance of fiber-reinforced concrete. Constr Build Mater
2017; 140:31-5.

[11] Anil Ö, Kantar E, Yilmaz MC. Low velocity impact behavior of RC slabs with different support types. Constr Build Mater 2015;93:1078-88.

[12] Radnić J, Matešan D, Grgić N, et al. Impact testing of RC slabs strengthened with CFRP strips. Compos Struct 2015;121:90-103.

[13] Sakthivel P, Ravichandran A, Alagamurthi N. Impact strength of hybrid steel meshand-fiber reinforced cementitious composites. KSCE J Civil Eng 2015;19(5):1385-95.

[14] Yahaghi J, Muda ZC, Beddu SB. Impact resistance of oil palm shells concrete reinforced with polypropylene fibre. Constr Build Mater 2016;123:394-403.

[15] Elavarasi D, Mohan KSR. On low-velocity impact response of SIFCON slabs under drop hammer impact loading. Constr Build Mater 2018;160:127-35.

[16] Nia AA, Hedayatian M, Nili M, et al. An experimental and numerical study on how steel and polypropylene fibers affect the impact resistance in fiber-reinforced concrete. Int J Impact Eng 2012;46:62-73.

[17] Gopinath S, Ayashwarya R, Kumar VR, et al. Low velocity impact behaviour of ultra high strength concrete panels. Sadhana 2014;39(6):1497-507.

[18] Othman H, Marzouk H. Finite-element analysis of reinforced concrete plates subjected to repeated impact loads. J Struct Eng 2017;143(9):04017120.

[19] Xiao Y., Li B., Fujikake K. Predicting response of reinforced concrete slabs under low-velocity impact. Mag Concrete Res2017;69;996-1010.

[20] Zhao W, Guo Q, Dou X, et al. Impact response of steel-concrete composite panels: experiments and Fe analyses. Steel Compos Struct 2018;26:255-63.

[21] Pham TM, Hao Y, Hao H. Sensitivity of impact behaviour of RC beams to contact stiffness. Int J Impact Eng 2018;112:155-64.

[22] Hillerborg A, Modéer M, Petersson P-E. Analysis of crack formation and crack growth in concrete by means of fracture mechanics and finite elements. Cement Concrete Res 1976;6(6):773-81.

[23] Bažant ZP, Oh BH. Crack band theory for fracture of concrete. Matériaux et Construction 1983;16(3):155-77.

[24] Prasad M, Krishnamoorthy C. Computational model for discrete crack growth in plain and reinforced concrete. Comput Methods Appl Mech Eng 2002;191(25-26):2699-725.

[25] Gálvez J, Červenka J, Cendon D, et al. A discrete crack approach to normal/shear cracking of concrete. Cement Concrete Res 2002;32(10):1567-85.

[26] Rao KB, Desai VB, Mohan DJ. Probabilistic analysis of mode II fracture of concrete with crushed granite stone fine aggregate replacing sand. Constr Build Mater 2012;27(1):319-30.

[27] Kumar CNS, Rao TG. Punching shear resistance of concrete slabs using mode-II fracture energy. Eng Fract Mech 2012;83:75-85.

[28] Gui Y-L, Bui HH, Kodikara J, et al. Modelling the dynamic failure of brittle rocks using a hybrid continuum-discrete element method with a mixed-mode cohesive fracture model. Int J Impact Eng 2016;87:146-55.

[29] Tompkins D, Khazanovich L, Bolander J. Lattice modelling of fracture in composite concrete pavements and overlays. Int J Pavement Eng 2015;16(1):56-68.

[30] Ramsamooj D. Fracture of highway and airport pavements. Eng Fract Mech 1993;44(4):609-26.

[31] Ramsamooj D, Lin G, Ramadan J. Stresses at joints and cracks in highway and airport pavements. Eng Fract Mech 1998;60(5-6):507-18.

[32] Roesler JR, Khazanovich L. Finite-element analysis of portland cement concrete pavements with cracks. Transp Res Rec 1997;1568(1):1-9.

[33] Ioannides AM. Fracture mechanics in pavement engineering: the specimen-size effect. Transp Res Rec 1997;1568(1):10-6.

[34] Liu J, Zhang X, Zollinger DG. Two-Step fracture mechanics-based approach to assess early-age delamination distress. Transp Res Rec 2007;2016(1):76-84.

[35] Aure TW, Ioannides AM. Simulation of crack propagation in concrete beams with cohesive elements in abaqus. Transp Res Rec 2010;2154(1):12-21.

[36] Aure TW, Ioannides AM. Numerical analysis of fracture process in pavement slabs. Can J Civil Eng 2012;39(5):506-14.

[37] Aure TW, Ioannides AM. Fracture analysis of aggregate interlock jointed slabs-ongrade. Constr Build Mater 2015;77:340-8.

[38] Ma K, Tang C, Wang L, et al. Stability analysis of underground oil storage caverns by an integrated numerical and microseismic monitoring approach. Tunn Undergr Space Technol 2016;54:81-91.

[39] Feng C, Li S, Liu X. Semi-spring contact model and its application to failure simulation of slope. Chin J Theor Appl Mech 2011;43:184-92.

[40] Zhang Q, Yue J, Liu C, et al. Study of automated top-coal caving in extra-thick coal seams using the continuum-discontinuum element method. Int J Rock Mech Min Sci 2019;122:104033.

[41] Feng C, Zhang J, Zhang Q, et al. Hematite's dynamic compressive strength and crushing features under impact load. J Zhengzhou Univ (Natl Sci Ed) 2019.

[42] Wang H, Bai C, Feng C, et al. An efficient CDEM-based method to calculate full-scale fragment field of warhead. Int J Impact Eng 2019;133:103331. 